Нармін ФАТУЛЛАСВА, orcid.org/0000-0002-0717-8042

аспірантка кафедри англійської філології Прикарпатського національного університету імені Василя Стефаника (Івано-Франківськ, Україна) narminfatullaevaа@gmail.com

\title{
МОВЛЕННСВА ФОРМУЛА ВИБАЧЕННЯ ЯК СКЛАДНИК КОНЦЕПТУ «ВВІЧЛИВІСТЬ» (НА МАТЕРІАЛІ РОМАНУ ДЖОДЖО МОЙСС “THE LAST LETTER FROM YOUR LOVER")
}

\begin{abstract}
У статті аналізується концепт «ввічливість» і комунікативна категорія «вибачення» як складник концепту «ввічливість» в англомовній художній прозі, який є обов 'язковим елементом успішного та безконфліктного спілкування (на матеріалі роману Джоджо Мойєс “The Last Letter from Your Lover”).

Метою вивчення ввічливості на теоретичному рівні є розуміння того, як засобами ввічливості люди успішно керують міжособистісними відносинами для досягнення свойх інтересів. Мовленнєвий акт вибачення пов 'язаний із дотриманням комунікативної дистаниії. Це доводить, щчо його необхідно розглядати в парадигмі стратегї ввічливості, оскільки головна прагматична мета вибачення полягає у переконанні адресата в тому, щзо його поважають і хочуть підтримати з ним безконфліктні стосунки.

Для досягнення мети дослідження та розв'язання конкретних завдань було використано загальнонаукові та спеціальні лінгвістичні методи дослідження на матеріалі роману Джоджо Мойєс “The Last Letter from Your Lоvеr”, зокрема методи аналізу, синтезу, психологічний, описовий, порівняльний, семантико-стилістичний, кількісний.

Результати дослідження показують, щзо вирази з вибаченням поширені як у будь-якій лінгвокультурі, так $i$ в англійській мові. Комунікативна категорія «вибачення» є невід'ємним складником кониепту «ввічливість», оскільки формули вибачення виконують важливу соціальну функцію в англійській мові, а саме відновлюють соиіальний баланс та гармонію між учасниками мовленнєвої взаємодії. Ця категорія є засобом реалізації важливої соиіальної функиії та найчастіше передає шкодування і жаль. Дослідження, яке ми провели на теоретичному рівні на матеріалі роману Джоджо Мойєс “The Last Letter from Your Lover” дають змогу стверджувати, шчо мовленнєві формули із семантикою вибачення є невід'ємною частиною англійської культури.

Ключові слова: концепт, мовленнєва формула, комунікативна категорія, мовленнєва взаємодія, культурний феномен, англійський мовленнєвий етикет.
\end{abstract}

Narmin FATULLAYEVA, orcid.org/0000-0002-0717-8042

Graduate Student at the Department of English Philology Vasyl Stefanyk Precarpathian National University (Ivano-Frankivsk, Ukraine) narminfatullaevaa@gmail.com

\section{SPEECH FORMULA OF APOLOGY AS A COMPONENT OF THE CONCEPT OF POLITENESS (BASED ON MATERIAL OF THE NOVEL BY JOJO MOYES "THE LAST LETTER FROM YOUR LOVER")}

The article analyzes the concept of "politeness" and the communicative category of "apology" as part of the concept of "politeness" in English fiction, which is a necessary element of successful and conflict-free communication, based on Jojo Moyes's novel "The Last Letter from Your Lover".

The purpose of the study of politeness at the theoretical level is to understand how by means of politeness people successfully manage interpersonal relationships to achieve their interests. The verbal act of apology is certainly related to communicative distance, and this proves that it should be considered in the paradigm of politeness strategy, as the main pragmatic goal of apology is to convince the recipient that he is respected and want to maintain a conflict-free relationship.

To achieve the goal of research and solve specific problems, general and special linguistic research methods were used on the material of Jojo Moyes 's novel "The Last Letter from Your Lover”, in particular: analysis, synthesis, psychological, descriptive, comparative, semantic-stylistic, quantitative.

The results of the study show that expressions of apology are common in any language culture as in English. Also, the communicative category of "apology" is an integral part of the concept of "politeness", as apology formulas perform an important social function in English, namely the restoration of social balance and harmony between the participants 
in speech interaction. This category is a means of realizing an important social function and often conveys regret. Thus, our theoretical research on Jojo Moyes's "The Last Letter from Your Lover" allows us to affirm that apologetic speech formulas are an integral part of English culture.

Key words: concept, speech formula, communicative category, speech interaction, cultural phenomenon, English speech etiquette.

Постановка проблеми. Людську діяльність важко уявити без мовного спілкування. Обов'язковим елементом успішного, безконфліктного і благополучного мовного акту є ввічливість, яка $\epsilon$ одним із базових складників міжособистісного спілкування. Ефективність комунікаційної взаємодії учасників визначається не лише знанням мови, але й володінням національно-культурною специфікою мовної і немовної поведінки, оперуванням соціально-культурними нормами. Суттєвим є знання культури народу, його цінностей, традицій, розуміння його світогляду і світосприйняття. Помилки, допущені щодо культурних норм, сприймаються украй негативно і можуть мати серйозні наслідки.

Головною причиною непорозуміння у міжкультурному спілкуванні є відмінність національної самосвідомості комунікаторів, а не відмінність мов. Дослідники підкреслюють, що при спілкуванні $з$ іноземцями люди легко вибачають граматичні та лексичні помилки, пояснюючи це браком лінгвістичних знань, однак вони дуже вразливі до порушення норм ввічливості, оскільки вважають, що вони були допущенні навмисно. В основі світосприйняття кожної нації лежить оригінальна система соціальних стереотипів, предметних цінностей, тому свідомість людини $є$ етнічно зумовленою. У цій статті ми детальніше розглянемо комунікативну категорію «вибачення» як складник концепту «ввічливість» в англомовній художній прозі, який $є$ обов'язковим елементом успішного й безконфліктного спілкування.

Метою вивчення ввічливості на теоретичному рівні $\epsilon$ розуміння того, як засобами ввічливості люди успішно керують міжособистісними відносинами для досягнення своїх інтересів.

Для досягнення мети дослідження та розв'язання конкретних завдань було використано загальнонаукові та спеціальні лінгвістичні методи дослідження: описовий метод - для опису ключових понять дослідження та для виявлення, класифікації й представлення відібраного мовного матеріалу; лексико-семантичний аналіз - для виокремлення семантичних полів і з'ясування частиномовної приналежності лексичних одиниць; семантико-стилістичний метод дозволяє виявити й описати мовні засоби, якими виражається концепт «ввічливість» i комунікативна категорія «вибачення»; кількісний метод вживається для уточнення та порівняння отриманих емпіричних показників на різних етапах дослідження; визначення поняттєвих і лексико-семантичних домінант у структурі аналізованого концепту. Актуальними у сфері міжкультурного спілкування є питання, пов'язані із співвідношенням культури і мови, до яких і відноситься проблема концепту ввічливості.

Аналіз досліджень. Розглянемо ближче концепт «вибачення» та категорію «вибачення», які привертали особливу увагу дослідників, оскільки вони поширені в будь-якій лінгвокультурі і $є$ засобом реалізації важливої соціальної функції. Ввічливість є об'єктом дослідження як вітчизняних (Е. Вєтрова (4), Л. Гнатюк (5), Н. Журавльова (7), О. Миронюк (12), В. Сухомлинський (15), так і зарубіжних вчених (В. Алпатов (1), Р. Бенаккьо (2), Е. Земская (8), Т. Ларина (10), Н. Формановская (16), R. Huszcza (17), R. Lakoff (18), M. Marcjanik (19), K. Ożóg (22), M. Sifianou (23) та інші). Як мовленнєвий акт вибачення розглянули Т. Буренко (3), С. Дорда (6), В. Карабан (9), Р. Ратмайр (13), M. Owen (21).

Виклад основного матеріалу. При вивченні комунікативної свідомості народу велику роль відіграє дослідження комунікативних категорій, а також знання концептів, пов'язаних з його комунікативною діяльністю. Концептосфера кожного народу має свої особливості. Згідно визначення Ю.Степановаконцептиєосновнимосередкомкультури в ментальному світі людини, що робить особливо важливим їх вивчення при розгляді питань міжкультурної комунікації (Степанов, 1997: 40).

Розглядаємо ввічливість як форму спілкування людини $з$ людьми, в основі якої лежить почуття власного достоїнства, вираження стриманого, коректного, делікатного ставлення до людей. Словник з етики подає ввічливість як моральну якість, що характеризує поведінку людини, для якої повага до людей стала повсякденною нормою поведінки. Мовна ввічливість, наголошує Н. Журавльова, - «це мистецтво виражати зовнішніми знаками ту внутрішню повагу, яку ми відчуваємо до іншої особи» (Журавльова, 2012: 7).

Загалом ввічливість - це культурний феномен, який включає уважність, позитивність, зовнішній вияв доброзичливості, освіченість, готовність зробити послугу, делікатність. Р. Лакофф у своїх роботах зазначала, що «ввічливість використовується для зменшення розбіжностей у спілку- 
ванні і є виявом поваги до іншої особи або осіб» (Lakoff, 1973: 64). Це поняття репрезентує національно-специфічну комунікативну категорію, яка становить складну систему стратегій комунікативної поведінки, спрямованих на сприятливе безконфліктне спілкування і дотримання суспільно-прийнятих норм.

О. Миронюк розглядає ввічливість як «шанобливе ставлення один до одного, дотримання почуття такту, коректності, міри», «мистецтво виражати зовнішніми знаками ту внутрішню повагу, яку ми відчуваємо до співрозмовника», ввічлива поведінка «має бути щирою й доброзичливою» (Миронюк, 2006: 8). Дослідниця описує принципи реалізації ввічливої поведінки, «на основі яких актуалізується соціально-рольовий аспект спілкування» (Миронюк, 2006: 9), і стверджує, що за допомогою мовних засобів «встановлюються та підтримуються соціальні дистанції між людьми, які змінюються залежно від тональності спілкування» (Миронюк, 2006: 10).

Дослідження ввічливості має міждисциплінарний характер і цікавить багатьох науковців різних галузей, зокрема лінгвістики, психології, соціології, філософії, етики, оскільки міжособистісне спілкування формує суспільне життя і $є$ основним чинником творення соціуму.

Лінгвістична ввічливість пов'язана з моральним аспектом спілкування, 3 комунікативною етикою як системою національно-специфічних правил і норм поведінки, що накопичує людський досвід у сфері моралі спілкування і розпорядчої норми поведінки в процесі комунікації. Виділяємо три етапи дослідження лінгвістичної ввічливості / неввічливості:

a) до першого етапу, який називається «грайсівським», належать роботи, які базуються на основних положеннях лінгвофілософії П. Грайс і Дж. Остіна, а також класичні теорії ввічливості Р. Лакофф, П. Браун, С. Левінсона, Дж. Ліча;

б) другий етап - дискурсивний або постмодерністський напрям у вивченні лінгвістичної ввічливості / неввічливості, який розробили вчені М. Лохер, Р. Уоттс, С. Міллз, Г. Ілен, Дж. Калпепер. Він зародився на початку $90-\mathbf{x}$ років XX століття як реакція на недоліки «Універсальної теорії ввічливості» П. Брауна і С. Левінсона;

в) третій етап у дослідженні лінгвістичної ввічливості / неввічливості пов'язаний з поворотом в напрямі соціологічного (інтеракційного) підходу, який дозволяє вченим запропонувати своє тлумачення переданого значення, виведеного досвідченим шляхом, не вдаючись до оцінок комунікантів.
Дослідники виокремлюють чіткі групи комунікативної поведінки, за допомогою яких реалізується ввічливість: greeting (вітання), farewell (npoщзання), apologizy (вибачення), gratitude (подяка), congratulation (привітання), wishes (побажання), acquaintance (знайомство), condolence (співчуття), treatment (звертання), request (прохання), invitation (запрочення), advice (порада), compliment (комплімент).

Мовленнєвий акт вибачення пов'язаний із дотриманням комунікативної дистанції. Це доводить, що його необхідно розглядати в парадигмі стратегії ввічливості, оскільки головна прагматична мета вибачення полягає в переконанні адресата у тому, що його поважають і хочуть підтримати з ним безконфліктні стосунки.

В англійській мові вибачення використовується для регулювання міжособистісних відносин в разі усвідомлення порушень соціальних конвенцій (навмисних чи ненавмисних). Правила етикету, норми етики в міжособистісних стосунках, які заподіюють фізичні й моральні страждання іншій особі, погіршують і соціальний імідж першої особи. Отже, мовний акт вибачення допомагає комунікантам регулювати міжособистісну дистанцію та підтримувати соціальний імідж.

Британська комунікативна культура належить до індивідуалістичного типу, а індивідуалізм означає «віру в першочерговість індивідуума, установку на самодостатність і особисту свободу, відповідальність за самого себе і право на особистий вибір» (Леонтович, 2003: 198). Основною рисою англійського етикету є попереджувальна ввічливість до оточуючих, тому англійці звертаються до мовного акту етикетного вибачення в будь-якій ситуації.

В англійській мові виділяються п'ять основних лексем для передачі семантики вибачення: "sorry", "pardon", "forgive", "apology", "excuse". Розглянемо детальніше реалізацію мовленнєвого акту вибачення в англомовній художній прозі. Так, мовні формули вибачення "Excuse me", "Sorry", "I am sorry (I'm sorry)" використовуються у повсякденному житті при спілкуванні з малознайомими та незнайомими людьми в публічних місцях. Відповіддю в таких ситуаціях здебільшого $є$ вербальна або невербальна реакція, яка підтверджує формальний дозвіл чи вибачення:

"Jennifer felt as if she had been caught snooping. "I'm so sorry. As I said, my memory is a little unreliable at the moment. Please don't think it reflects"

Mrs. Cordoza shook her head" (Moyes, 2010: 64).

"Do excuse me for one moment". Jennifer holds her hand over the receiver. "I'm so sorry", she says. 
"I'm likely to be some time". Her voice suggests that their conversation will not be continued today.

"Someone needs to apply for compensation".

"Can we talk again?" Ellie holds out the piece of paper. "My details are there. I really want to know".

Jennifer nods, half her attention on her caller.

"Yes. Of course. It's the least I can do. And thank you again, Ellie" (Moyes, 2010: 318).

Найчастіше вживаною мовленнєвою формулою в англійській мові $є$ формула "I am sorry (I'm sorry)". У цьому випадку виявляється така риса англійської поведінки як дистанційованість, неприпустимість прямого впливу на адресата:

"Which part of London is it in?" he said.

"I'm sorry, I have no idea. I thought you might know".

He frowned. "There's an Alberto's club in Mayfair. I can take you there, but I'm not sure it'll be open" (Moyes, 2010: 104).

"Jennifer felt the woman's assessing gaze on her. It was not entirely friendly. "Are you open?"

"Do we look open?"

She held her bag to her stomach, suddenly self-conscious. "I'm sorry. I'll come back another time" (Moyes, 2010: 104).

Ця формула має формальний маркер ввічливості, який виражає жалкування адресата, але це його ні до чого не зобов'язує.

"I'm sorry", he continued, "but I don't want a sandwich. I don't want to sit in this place listening to ruddy string music. If I've earned anything through being apparently dead for the last four years, it must be the right not to have to sit through tea and polite conversation".

"Ijust wanted to see yo." (Moyes, 2010: 218).

"She held his gaze for a moment, then glanced at her watch". "I need to leave".

He winced. "I'm sorry. I won't say another thing. I just need to know"

"It's not you. Really. I do need to be somewhere" (Moyes, 2010: 218).

"Where did you get these?" he says.

"They were here", she says tentatively, afraid of what this information will do to him.

"Here?"

"Buried. In your library".

He glances around him, as if these empty shelves can provide some clue to what she's saying.

"I'm sorry. I know they're personal".

"How did you know they were mine?"

"It's a long story" (Moyes, 2010: 406).

Мовна формула "I am sorry (I'm sorry)" $є$ найбільш частотним засобом в англійській мові, у якому фактично втрачено семантичне значення.
Ця формула часто використовується просто як сигнал про увагу. Частотність вживання і семантична спустошеність вказаної мовленнєвої формули може викликати здивування у представників інших культур.

"This is for you", she said brusquely.

Jennifer took it from her. She opened it, and immediately placed her hand on top of the papers as the wind threatened to whip them away.

"Don't lose any of them". It was an instruction.

"I'm sorry. I don't understand. What are these?"

"They are the people he has paid off" (Moyes, 2010: 236).

"Do you think he'd be loyal to you?"

She held his gaze for a moment, then glanced at her watch. "I need to leave".

He winced. "I'm sorry. I won't say another thing. Ijust need to know"

"It's not you. Really. I do need to be somewhere".

He caught himself. "Of course. I'm sorry. I'm the one who was late. I'm sorry to have wasted your time". He couldn't help the anger in his voice. He cursed his editor for losing him that precious half hour, cursed himself for what he already knew were wasted opportunities - and for allowing himself to come close to something that still had the power to burn him" (Moyes, 2010: 219).

"She sees his surprise. He leans forward. "Wow. She actually called you. What happened?"

Suddenly she begins to cry again, tears pouring. "I'm sorry," she mutters, scrambling for tissues. "I'm sorry. I don't know why I'm being so ridiculous" (Moyes, 2010: 343).

Також цей засіб вибачення підсилюється за допомогою повторів або вживання кількох мовленнєвих формул:

"When she arrives, he is already sitting at a table, oddly "out of place among the construction workers in his Paul Smith jacket and soft, pale shirt. "I'm sorry", he says, even before she sits down. "I'm so sorry. She had my phone. I thought I'd lost it. She got hold of a couple of e-mails I hadn't deleted and found your name the rest" (Moyes, 2010: 402).

"Do excuse me for one moment". Jennifer holds her hand over the receiver. "I'm so sorry," she says. "I'm likely to be some time". Her voice suggests that their conversation will not be continued today. "Someone needs to apply for compensation".

"Can we talk again?" (Moyes, 2010: 318).

"I was once told by someone wise that writing is perilous, as you can't always guarantee your words will be read in the spirit in which they were written. So I'm going to be straightforward. I'm sorry. Forgive me. If there is any way I can change your 
opinion of me, please let me know". They had been the easiest words to write in the whole piece" (Moyes, 2010: 419).

Мовленнєва формула "Excuse me" зустрічається рідше, ніж попередня формула. Ця формула $\epsilon$ імперативною, містить спонукання до адресата. Окрім прямого вибачення, вона здебільшого використовується для привертання уваги або звернення уваги на якесь невдоволення, реалізується 3 підвищеною інтонацією:

"Sorry," she said, "but your boy is here".

It took Anthony several seconds to grasp that she was looking at him. "My boy?"

"I've put him in Don's office".

Anthony stood up, barely able to digest what he had heard. "Excuse me a moment", he said, and followed Cheryl out across the newsroom" (Moyes, 2010: 390).

"Do excuse me for one moment". Jennifer holds her hand over the receiver. "I'm so sorry", she says. "I'm likely to be some time". Her voice suggests that their conversation will not be continued today. "Someone needs to apply for compensation" (Moyes, 2010: 318).

Мовленнєві формули 3 “apology" зустрічаються в усному мовленні рідше. Носії мови намагаються не вживати у своєму мовленні перформативні дієслова, що пояснює нечасте вживання цієї мовної формули. Мовленнєві формули з apology вживаються для уникнення неоднозначності або у більш формальних відносинах. Найчастіше їх можна зустріти в публічних вибаченнях:

"Yesterday was such a shock", she said finally, placing her cup on the saucer. "I must apologize for how I behaved. You must have thought I was very odd" (Moyes, 2010: 215)

"Please allow me to apologize. If I could buy you and Mr. Stirling lunch before I return to London I'd be very glad to make it up to you" (Moyes, 2010: 77).

Мовленнєва формула “pardon” в англійській мовній культурі зустрічається украй рідко. Участь цієї лексеми у мові є скоріше конвенціональною, тобто зумовленою звичаями. Ця формула часто вживається при перепитах:

"She heard the scornful laughter and tilted her chin a little higher. "You'd do well to learn that you'll only progress at Acme Mineral and Mining with a professional attitude".

"And loose knicker elastic", muttered someone behind her.

"I beg your pardon?"

"Nothing, Miss Parker" (Moyes, 2010: 229).

"If you could just put your signature there". Mr. Grosvenor pointed with a beautifully manicured finger "and there. Then, of course, we'll need your husband's signature here". He smiled again, his lips wavering a little.

"Oh, you'll need to send them to him directly", she said.

\section{"I beg your pardon?"}

"Ino longer live with my husband. We communicate by letter" (Moyes, 2010: 336).

Мовленнєві формули 3 "forgive" є маловживаними в британській мовній культурі. Лінгвісти підкреслюють, що формули за участю цієї лексеми не $є$ типовими формулами вибачення, можуть використовуватися для посилення вибачення:

"Of course. Please forgive me, but I still can't remember things as well as I might. I don't remember you mentioning your husband" (Jojo Moyes "The Last Letter from Your Lover" (Moyes, 2010: 64).

"He turns slowly toward her and fixes her with what her mother might have termed an old-fashioned look. "We in the library may be considered something not far short of an irrelevance by you and your ilk, Miss Haworth, but at my age I stop a little short of office dogsbody. Forgive me if that inconveniences your social life" (Moyes, 2010:298).

"I was once told by someone wise that writing is perilous, as you can't always guarantee your words will be read in the spirit in which they were written. So I'm going to be straightforward. I'm sorry. Forgive me. If there is any way I can change your opinion of me, please let me know". They had been the easiest words to write in the whole piece" (Moyes, 2010: 419).

Мовленнєва формула "I am afraid (I'm afraid)" також може виражати семантику вибачення:

"The Stirlings were about to step into the elevator. He could just see her through the crowd. "I need to speak to someone. I'll be two minutes".

"Sir, I'm afraid I can't let you in without" (Moyes, 2010: 121).

"I'm very sorry, Melissa. I had to wait in for a plumber, and"

"Let's not, Ellie," she says quietly. "I'd rather you didn't insult my intelligence. And unless you're going to be able to convince me that you have a plumber in attendance almost every other day of the week, I'm afraid I have to conclude that you're not taking this job very seriously" (Moyes, 2010: 296).

Здійснивши дослідження вважаємо, що вирази iз вибаченням в англійській мові найчастіше передають шкодування і жаль.

У відповідь на вибачення носії британської культури намагаються переконати адресата у тому, що відносини не пошкоджені. Т. Ларіна зазначає: «У відповідь на вибачення англійські комуніканти підкреслюють незначність нанесеного збитку 
або принесених незручностей i охоче запевняють адресата в тому, що втрачену рівновагу відносин відновлено» [10]. Традиційними репліками у таких випадках є ok (it's ok); that's (it's) all right; no problem; do not worry; never mind.

Внаслідок аналізу мовленнєвого акту вибачення в романі Джоджо Мойєс "The Last Letter from Your Lover" ми виокремили 181 одиницю, які виражали висловлення 3 формулою вибачення. Мовленнєва формула "sorry” зустрічалася 101 раз, що становить 55\%; "excuse” трапляється рідше і становить 11,6\% (21 одиниця); мовленнєві формули з “apology” виявили у 12\% випадків (23 одиниці); "forgive” - у 14\% (26 одиниць); маркер "pardon" зустрічається в 1\% (2 одиниці); формула із семантикою вибачення "I am afraid (I'm afraid)" займає $4,4 \%$ (8 одиниць).

Висновки. Результати дослідження дають змогу стверджувати, що мовленнєві формули із семантикою вибачення є невід'ємною частиною англійської культури. В англійській мові виділяються п'ять основних лексем для передачі семантики вибачення, які включають “sorry”, "pardon”, "forgive", “apology", "excuse”. Кожна формула має свою специфіку використання.

Мовні формули вибачення "Excuse me", "Sorry”, "I am sorry (I'm sorry) ” використовуються у повсякденному житті при спілкуванні з малознайомими та незнайомими людьми у публічних місцях. Найчастіше вживаною мовленнєвою формулою в англійській мові є формула "I am sorry (I'm sorry)”. У цьому випадку виявляється така риса англійської поведінки як дистанційованість, неприпустимість прямого впливу на адресата. Ця лексема $\epsilon$ формальним маркером ввічливості, який виражає жалкування адресата, але це його ні до чого не зобов'язує.

Мовна формула "I am sorry (I'm sorry)" $є$ найбільш частотним засобом в англійській мові, у якому фактично втрачено семантичне значення. Ця формула часто використовується просто як сиг- нал про увагу. Частотність вживання і семантична спустошеність вказаної мовленнєвої формули може викликати здивування у представників інших культур. Мовленнєва формула "Excuse me" є імперативною, містить спонукання до адресата. Окрім прямого вибачення, вона використовується для привертання уваги або звернення уваги на якесь невдоволення, реалізується 3 підвищеною інтонацією.

Носії мови намагаються не вживати у своєму мовленні перформативні дієслова, що пояснює нечасте вживання мовленнєвих формул 3 “apology". Цей засіб вони використовуються для уникнення неоднозначності або у більш формальних відносинах (найчастіше їх можна зустріти в публічних вибаченнях). Участь лексеми "pardon" у мові є скоріше конвенціональною, тобто зумовленою звичаями. Ця формула часто вживається при перепитах. Формули за участю лексеми "forgive" не є типовими формулами вибачення, можуть використовуватися для посилення вибачення.

Отже, результати дослідження показують, що комунікативна категорія вибачення є невід'ємним складником концепту «ввічливість», оскільки формули вибачення виконують важливу соціальну функцію в англійській мові, а саме відновлюють соціальний баланс та гармонію між учасниками мовленнєвої взаємодії.

Мовленнєвий акт вибачення пов'язаний iз дотриманням комунікативної дистанції. Це доводить, що його необхідно розглядати в парадигмі стратегії ввічливості, оскільки головна прагматична мета вибачення полягає в переконанні адресата у тому, що його поважають і хочуть підтримати з ним безконфліктні стосунки. До того ж комунікативні формули з семантикою вибачення вживаються не тільки для вираження вибачення, їх вживання в англійській мові досить варіативне. Тому можна стверджувати, що мовні формули з семантикою вибачення є невід'ємною частиною повсякденного спілкування.

\section{СПИСОК ВИКОРИСТАНИХ ДЖЕРЕЛ}

1. Алпатов В. М. Категории вежливости в современном японском языке / В. М. Алпатов. Москва : Наука, 1978.109 с.

2. Бенаккьо Р. Конкуренция видов, вежливость и этикет в русском императиве. Russian Linguistics. 2002. 149-178 с.

3. Буренко Т. М. Когнітивно-прагматичні характеристики мовленнєвого акту вибачення в англомовному дискурсі XVI - XXI століть : автореф. дис. на здобуття наук. ступеня канд. філол. наук: спец. 10.02.04 «Германські мови»/ Т. М. Буренко. Харків, 2008. 20 с.

4. Вєтрова Е. С. Семантика і функціонально-комунікативний аспект етикетних одиниць в епістолярній спадщині українських письменників XIX ст. : автореф. дис. канд. філол. наук: 10.02.01 «Українська мова» / Е. С. Вєтрова. Донецьк, 2004. 20 с.

5. Гнатюк Л. П. Прагматичні й функціонально-комунікативні аспекти ввічливості (на матеріалі сучасної української мови) : автореф. дис. канд. філол. наук: 10.02.01 «Українська мова» / Л. Гнатюк. Івано-Франківськ, 2007.18 с.

6. Дорда С. В. Комунікативно-прагматичні особливості висловлювань, які передають каяття (на матеріалі англійської мови) : автореф. дис. на здобуття наук. ступ. канд. філол. наук: спец. 10.02.04 «Германські мови» / С. В. Дорда. Київ, 1996. 16 с. 
7. Журавльова Н. М. Поетика української епістолярної ввічливості XIX - початку XX століття / Наталя Журавльова. Запоріжжя : Запорізький національний університет, 2012. 548 с.

8. Земская Е. А. Категория вежливости: общие вопросы национально-культурной специфики русского языка. Zeischrift fur Slavische Philologie. 1997. 271-301 c.

9. Карабан В. И. Сложные речевые единицы: прагматика английских асиндетических полипредикативных образований / В. И. Карабан. Киев : Высш. шк., 1989. 131 с.

10. Ларина Т. В. Категория вежливости и стиль комуникации. Сопоставление английських и русских лингвокультурных традиций : монография. Москва : Рукописные памятники Древней Руси, 2009.

11. Леонтович О. А. Россия и США: введение в межкультурную коммуникацию / О. А. Леонтович. Волгоград : Перемена, 2003. 399 с.

12. Миронюк О. М. Історія українського мовного етикету. Звертання / О. М. Миронюк. Київ : Логос, 2006. 167 с.

13. Ратмайр Р. Прагматика извинения: сравнительное исследование на материале русского языка и русской культуры / Р. Ратмайр. Москва, 2003. 272 с.

14. Степана Ю. С. Константи. Словник російської культури. Досвід дослідження. Москва, 1997.

15. Сухомлинський В. О. Слово про слово. Вибрані твори: У 5 т. Київ, 1977.

16. Формановская Н. И. Речевое взаимодействие: коммуникация и прагматика / Н. И. Формановская. Москва : ИКАР, 2007. $480 \mathrm{c}$.

17. Huszcza R. Honoryfikatywność. Gramatyka. Pragmatyka. Typologja / R. Huszcza. Warszawa : Wydawnictwo Naukowe PWN, 2006. 228 p.

18. Lakoff R. The logic of politeness, or minding your p's and q's. II Papers from the Ninth Regional Meeting of the Chicago Linguistics Society. / R. Lakoff. Chicago, 1973. 292-305 p.

19. Marcjanik M. Grzeczność w komunikacji językowej / M. Marcjanik. Warszawa : Wydawnictwo Naukowe PWN, 2007. $166 \mathrm{p}$.

20. Moyes J. The Last Letter from Your Lover. New-York : Penguin Group, 2010.

21. Owen M. Apologies and remedial exchanges. A study of language use in social interaction / M. Owen. Berlin : Mouton, 1983. $254 \mathrm{p}$.

22. Ożóg K. Zwroty grzecznościowe współczesnej Polszczyzny mówionej (na materiale języka mówionego mieszkańców Krakowa). Zeszyty Naukowe Uniwersytetu Jagiellońskiego CM XIII. Prace Językoznawcze. Zeszyt 98. Kraków, 1990. 92 p.

23. Sifianou M. Politeness Phenomena in England and Greece: a Cross-cultural Comparison / M. Sifianou. Oxford, 1992.

\section{REFERENCES}

1. Alpatov V. M. Kategorii vezhlivosti v sovremennom yaponskom yazyike / V. M. Alpatov. [Categories of politeness in modern Japanese]. Moskva : Nauka, 1978, p. 109 [in Russian].

2. Benakko R. Konkurentsiya vidov, vezhlivost i etiket v russkom imperative / R. Benakko // Russian Linguistics. [Competition of species, politeness and etiquette in the Russian imperative]. 2002, p. 149-178 [in Russian].

3. Burenko T. M. Kohnityvno-prahmatychni kharakterystyky movlennievoho aktu vybachennia v anhlomovnomu dyskursi XVI - XXI stolit : avtoref. dys. na zdobuttia nauk. stupenia kand. filol. nauk: spets. 10.02.04 "Hermanski movy" / T. M. Burenko. [Cognitive-pragmatic characteristics of the speech act of apology in the English-language discourse of the XVI - XXI centuries]. Kharkiv, 2008, p. 20 [in Ukrainian].

4. Vietrova E. S. Semantyka i funktsionalno-komunikatyvnyi aspekt etyketnykh odynyts $\mathrm{v}$ epistoliarnii spadshchyni ukrainskykh pysmennykiv XVI - XXI st. [Cognitive-pragmatic characteristics of the speech act of apology in the English-language discourse of the XVI - XXI centuries]. Avtoref. dys. kand. filol. nauk: 10.02.01 "Ukrainska mova" / E. S. Vietrova. Donetsk, 2004. 20 s. [in Ukrainian].

5. Hnatiuk L. P. Prahmatychni y funktsionalno-komunikatyvni aspekty vvichlyvosti (na materiali suchasnoi ukrainskoi movy) : avtoref. dys. kand. filol. nauk: 10.02.01 "Ukrainska mova" / L. Hnatiuk. [Pragmatic and functional-communicative aspects of politeness (on the material of the modern Ukrainian language)]. Ivano-Frankivsk, 2007. $18 \mathrm{~s}$. [in Ukrainian].

6. Dorda S. V. Komunikatyvno-prahmatychni osoblyvosti vyslovliuvan, shcho peredaiut kaiattia (na materiali anhliiskoi movy) : avtoref. dys. na zdobuttia nauk. stup. kand. filol. nauk: spets. 10.02.04 "Hermanski movy" / S. V. Dorda. [Communicative and pragmatic features of statements that convey repentance (on the material of the English language)]. Kyiv, 1996. 16 s. [in Ukrainian].

7. Zhuravlova N. M. Poetyka ukrainskoi epistoliarnoi vvichlyvosti KhIKh - pochatku KhKh stolittia / Natalia Zhuravlova. Zaporizhzhia : Zaporizkyi natsionalnyi universytet. [Poetics of Ukrainian epistolary politeness of the XIX -beginning of the XX century]. 2012. 548 s. [in Ukrainian].

8. Zemskaya E. A. Kategoriya vezhlivosti: obschie voprosyi natsionalno-kulturnoy spetsifiki russkogo yazyika / E. A. Zemskaya // Zeischrift fur Slavische Philologie. [Category of politeness: general issues of the national and cultural specifics of the Russian language]. 1997. 271-301 s. [in Russian].

9. Karaban V. I. Slozhnyie rechevyie edinitsyi: pragmatika angliyskih asindeticheskih polipredikativnyih obrazovaniy / V. I. Karaban. Kiev : Vyissh. shk. [Complex speech units: the pragmatics of English asyndetic polypredicative formations]. 1989. 131 c. [in Russian].

10. Larina T. V. Kategoriya vezhlivosti i stil komunikatsii. Sopostavlenie angliyskih i russkih lingvokulturnyih traditsiy: monografiya. Moskva : Rukopisnyie pamyatniki Drevney Rusi. [Courtesy category and communication style. Comparison of English and Russian linguocultural traditions : monograph. Moscow : Manuscript Monuments of Ancient Rus]. 2009. [in Russian]. 
11. Leontovich O. A. Rossiya i SShA: vvedenie v mezhkulturnuyu kommunikatsiyu / O. A. Leontovich. Volgograd : Peremena. Russia and the USA: an Introduction to Intercultural Communication]. 2003. 399 s. [in Russian].

12. Mironyuk O. M. Istorlya ukraYinskogo movnogo etiketu. Zvertannya / O. M. Mironyuk. KiYiv : Logos. [History of Ukrainian language etiquette]. 2006. 167 s. [in Ukrainian].

13. Ratmayr R. Pragmatika izvineniya: sravnitelnoe issledovanie na materiale russkogo yazyika i russkoy kulturyi / R. Ratmayr. Moskva. [The Pragmatics of Apology: a Comparative Study Based on the Material of the Russian Language and Russian Culture]. 2003. 272 s. [in Russian].

14. Stepana Yu. S. Konstanty. Slovnyk rosiiskoi kultury. Dosvid doslidzhennia. Moskva. [Dictionary of Russian culture. Research experience]. 1997. [in Ukrainian].

15. Sukhomlynskyi V. O. Slovo pro slovo. / V. O. Sukhomlynskyi // Vybrani tvory: U 5 t. [Word for word. / V. O. Sukhomlinsky // Selected works]. Kyiv, 1977 [in Ukrainian].

16. Formanovskaya N. I. Rechevoe vzaimodeystvie: kommunikatsiya i pragmatika / N. I. Formanovskaya. Moskva : IKAR. [Speech Interaction: Communication and Pragmatics]. 2007. 480 s. [in Russian]. 